\title{
A routine biomarker-based risk prediction model for metabolic syndrome in urban Han Chinese population
}

Wenchao Zhang ${ }^{1 \dagger}$, Qicai Chen ${ }^{2 \dagger}$, Zhongshang Yuan ${ }^{1}$, Jing Liu', Zhaohui Du', Fang Tang ${ }^{3}$, Hongying Jia ${ }^{4}$, Fuzhong Xue and Chengqi Zhang ${ }^{3^{*}}$

\begin{abstract}
Background: Many MetS related biomarkers had been discovered, which provided the possibility for building the MetS prediction model. In this paper we aimed to develop a novel routine biomarker-based risk prediction model for MetS in urban Han Chinese population.

Methods: Exploring Factor analysis (EFA) was firstly conducted in MetS positive 13,345 males and 3,212 females respectively for extracting synthetic latent predictors (SLPS) from 11 routine biomarkers. Then, depending on the cohort with 5 years follow-up in 1,565 subjects (male 1,020 and female 545), a Cox model for predicting 5 years MetS was built by using SLPs as predictor; Area under the ROC curves (AUC) with 10 fold cross validation was used to evaluate its power. Absolute risk (AR) and relative absolute risk (RAR) were calculated to develop a risk matrix for visualization of risk assessment.

Results: Six SLPs were extracted by EFA from 11 routine health check-up biomarkers. Each of them reflected the specific pathogenesis of MetS, with inflammatory factor (IF) contributed by WBC \& LC \& NGC, erythrocyte parameter factor (EPF) by Hb \& HCT, blood pressure factor (BPF) by SBP \& DBP, lipid metabolism factor (LMF) by TG \& HDL-C, obesity condition factor (OCF) by BMI, and glucose metabolism factor (GMF) by FBG with the total contribution of $81.55 \%$ and $79.65 \%$ for males and females respectively. The proposed metabolic syndrome synthetic predictor (MSP) based predict model demonstrated good performance for predicting 5 years MetS with the AUC of 0.802 ( $95 \% \mathrm{Cl}$ 0.776-0.826) in males and 0.902 ( $95 \% \mathrm{Cl} 0.874-0.925)$ in females respectively, even after 10 fold cross validation, AUC was still enough high with $0.796(95 \% \mathrm{Cl} 0.770-0.821)$ in males and 0.897 ( $95 \% \mathrm{Cl}$ 0.868-0.921) in females. More importantly, the MSP based risk matrix with a series of risk warning index provided a feasible and practical tool for visualization of risk assessment in the prediction of MetS.

Conclusions: MetS could be explained by six SLPs in Chinese urban Han population. The proposed MSP based predict model demonstrated good performance for predicting 5 years MetS, and the MetS-based matrix provided a feasible and practical tool.
\end{abstract}

Keywords: Metabolic Syndrome (MetS), Routine biomarkers, Predictor model, Risk matrix

\footnotetext{
* Correspondence: chengqizhangsd@126.com

'Equal contributors

${ }^{3}$ Health Management Center, Shandong Provincial QianFoShan Hospital,

Jinan 250014, China

Full list of author information is available at the end of the article
}

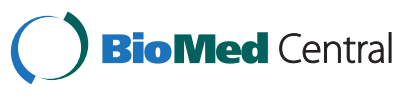

(c) 2015 Zhang et al.; licensee BioMed Central. This is an Open Access article distributed under the terms of the Creative Commons Attribution License (http://creativecommons.org/licenses/by/4.0), which permits unrestricted use, distribution, and reproduction in any medium, provided the original work is properly credited. The Creative Commons Public Domain Dedication waiver (http://creativecommons.org/publicdomain/zero/1.0/) applies to the data made available in this article, unless otherwise stated. 


\section{Background}

Metabolic syndrome (MetS) is a disorder with cooccurrence of several known cardiovascular risk factors, including insulin resistance, obesity, atherogenic dyslipidemia and hypertension [1]. With the economic development and the changing of people's lifestyle in china, the prevalence of MetS is increasing rapidly. Compared with Europeans and Americans, Asians are more likely to have MetS [2]. Data from the China Health and Nutrition Survey conducted in 2009 suggested that the prevalence rate of MetS has reached up to $21.3 \%$ among the Chinese adults [3]. Many studies indicated that incidence of MetS will increase the risk of type 2 diabetes [4], cardiovascular disease [5-9], renal damage $[10,11]$, and so on. Therefore, prediction of MetS is very essential for early prevention of the above diseases.

Some risk scores based on cross-sectional studies were structured for screening undiagnosed MetS [12-14], which depended on questionnaire survey about participants' lifestyle and medical histories. Although the area under the ROC curves for detecting the MetS in these studies were acceptable with a range from $72.4 \%$ to $80.1 \%$, cross-sectional study could only provide temporal information of the subjects. Cohort study is more preferable for risk assessment. Hsiao and Yang conducted a two-year (from 2003 to 2005) [15] and a 5-year followup study (during 1997-2006) [16] respectively in Chinese population. Both of them confirmed that routine checkup biomarkers like serum cholesterol, triglycerides, blood glucose, measurement of body height and weight, blood pressure et al., could be served as effective predictors to MetS using multivariate logistic regression (MLR). However, MLR is not suitable for survival data, and it also limited the applying of the model in the first study due to relative short follow-up time and small sample. In the second study stepwise regression has ruled out many MetS related biomarkers from the model. Fortunately, many other studies [17-29] have found a number of MetS related biomarkers, which provide us a convenience to build the risk appraisal model of MetS. After studying 6Synthetic Latent Predictors from 11 MetS routine biomarkers in a MetS positive population, we develop a novel routine biomarker-based risk prediction model for MetS in urban Han Chinese population.

\section{Methods}

Participants

Subjects were selected from the urban adult citizen who came to the Center for Health Management of Shandong Provincial QianFoShan Hospital, and the Health Examination Center of Shandong Provincial Hospital to conduct medical examination from 2005 to 2010. Among 92,284 subjects (aged 18 to 82 years) completing all steps of physical examination, 16,557 subjects were diagnosed with MetS at their first check-up year according to the criteria of the Chinese Medical Association. Of 75,727 subjects without MetS at baseline, 1,565 (1,020 males and 545 females) completed a 5-year follow-up and were included in the cohort study design. The cumulative incidence rate was calculated for 1,565 subjects who were followed up.

\section{Biomarkers selection and measurements}

In the present study, eleven biomarkers were selected from routine health check-up data, including body mass index (BMI), systolic blood pressure (SBP), diastolic blood pressure (DBP), fasting blood-glucose (FBG), triglycerides (TG), high-density lipoprotein cholesterol (HDL-C), hemoglobin $(\mathrm{Hg})$, hematocrit $(\mathrm{HCT})$, white blood cell count (WBC), lymphocyte (LC), neutrophile granulocyte (NGC). Among them, BMI, SBP, DBP, TG, HDL-C and FBG were selected based on the traditional definition of MetS. The others were included according to the available results of peer studies: Hb [17-19], HCT [17,18,28], WBC [20-27], LC $[23,29]$, NGC $[23,29]$. All measurements were conducted in the Center for Health Management of Shandong Provincial QianFoShan Hospital and the Health Examination Center of Shandong Provincial Hospital following same and standard procedures. Both of the two institutions are nationally accredited. The whole study was approved by the Ethics Committee of School of Public Health, Shandong University, and written informed consent was obtained from all eligible participants.

\section{Definition of MetS}

Chinese Medical Association Diabetes Branch criteria [30] were applied to define MetS in this paper. Subjects who had three or more of the following four signs were diagnosed with MetS: 1) overweight or obesity, BMI $\geq 25.0 \mathrm{Kg} / \mathrm{M}^{2}$; 2) hypertension, systolic/ diastolic $\geq 140 \mathrm{mmHg} / 90 \mathrm{mmHg}$ or previous diagnosis; 3) dyslipidemia, fasting $\mathrm{TG} \geq 1.7 \mathrm{mmol} / \mathrm{L}$ (110 mg/ $\mathrm{dl}$ ), or fasting high-density lipoprotein cholesterol (HDLC) $<0.9 \mathrm{mmol} / \mathrm{L}(35 \mathrm{mg} / \mathrm{dl})$; 4) hyperglycemia, fasting blood-glucose $(\mathrm{FBG}) \geq 6.1 \mathrm{mmol} / \mathrm{L}(110 \mathrm{mg} / \mathrm{dl})$ or $2 \mathrm{~h}$ Post-meal glucose $(\mathrm{PG}) \geq 7.8 \mathrm{mmol} / \mathrm{L}(140 \mathrm{mg} / \mathrm{dl})$, or previous diagnosis.

\section{Statistical analysis}

Descriptive statistics were conducted for 16,557 subjects with MetS at baseline. Student's $t$ test was used to detect the statistical significances for 11 biomarkers between males and females, and the $x^{2}$ test was conducted to detect the difference in the prevalence of the four basic components (obesity, hypertension, dyslipidemia and hyperglycemia) between males and females.

To eliminate multicollinearity between the routine check-up biomarkers and build a better model for MetS 
prediction, both Exploring factor analysis(EFA) and Cox proportional hazard regression model are applied in the present study. Finally, a MetS synthetic predictor (MSP) was developed through the following four steps: First, EFA with principal component algorithm and varimax rotation from correlation matrix was performed to extract independent MetS risk-related factors from the 11 routine check-up biomarkers in 16,557 subjects with MetS at baseline. The criteria for retaining factors in the present study was eigenvalue $>0.9$ (for keeping the accounting variations of total was greater than $70 \%$ ). Only variables that share a factor loading of at least 0.50 were used for further analytical interpretation and named factors. Second, a Cox regression model was built between the hazard function of MetS and the extracted factors in 1,565 subjects in the cohort study design: $\mathrm{h}(\mathrm{t})=\mathrm{h} 0(\mathrm{t}) \exp$ $\left(\beta_{0}\right.$ age $\left.+\beta_{1} \mathrm{~F}_{1}+\beta_{2} \mathrm{~F}_{2}+\ldots+\beta_{\mathrm{k}} \mathrm{F}_{\mathrm{k}}\right)$, and a MSP was developed by $M S P=\beta_{1} \mathrm{~F}_{1}+\beta_{2} \mathrm{~F}_{2}+\ldots+\beta_{\mathrm{k}} \mathrm{F}_{\mathrm{k}}$. Third, the risk of MetS, for the 1565 subjects from the cohort, was estimated by

$$
P(t)=1-S(t)=1-\exp \left(-\int_{0}^{t} h_{0}(u) \exp (B) d u\right)
$$

where, $P(t)$ was the predictive probability of MetS at year $t, B=\beta_{0}$ age $+\beta_{1} M S P$. For both training set and 10 fold cross validation, Receiver Operator Characteristics curve (ROC curve) analysis was conducted, and the area under the ROC curve (AUC) together with sensitivity, specificity, 95\% Confidence Interval and cut-off of $P$ value was calculated by MedCalc software [31]. The optimal cut-off was estimated based on the Youden index criterion [32] which is optimal in the sense that it provides a score which reflects the intention of maximizing the overall correct classification rate. Finally, Excess Absolute Risk (EAR) and Relative Absolute Risk(RAR) were calculated for 1,565 subjects from the five-year follow-up who had completed physical examinations and the 11 biomarker measurements by $E A R=P_{j}(t)-\bar{P}_{j}$ $(t)$ and $R A R=P_{j}(t) / \bar{P}_{j}(t)$ respectively, where $P_{j}(t)$ signified Absolute Risk (AR), namely the probability of MetS at year $t$, in which $j$ noted subject's age. $\bar{P}_{j}(t)$ signified the average probability of MetS at year $t$ in $j^{t h}$ age, which can be calculated by model (1) through $\bar{B}_{j}=\beta_{1} a g e_{j}+\gamma$ $\overline{M S P} j$, where $\overline{M S P} j$ was the mean of MSP in $j^{t h}$ age. All the steps were conducted in males and females respectively. The risk matrix for AR and RAR were depicted using ArcGIS 9.1, and all statistical analyses was performed using SAS 9.1.3 with $P<0.05$ considered statistically significant.

\section{Results}

The prevalence of MetS in the study was $17.9 \%(16,557 /$ $92,284)(22.7 \%$ in males and $9.6 \%$ in females) at baseline.
At the end of the follow-up period of 1,565 subjects, 348 incident MetS cases (286 males and 62 females) were diagnosed and the cumulative incidence rate was $22.2 \%$ ( $28 \%$ in males and $11.4 \%$ in females) (see Additional file 1: Table S1). The prevalence of four basic components (obesity, hypertension, hyperglycemia, and dyslipidemia) was significantly different between males and females (see Additional file 2: Table S2).

Table 1 showed the distribution of age and eleven biomarkers between males and females with MetS at baseline, indicating that all variables except BMI and LC were significantly different between males and females. Of them, DBP, TG, Hb, HCT, WBC and NGC were higher in males than in females, while age, SBP, FBG, and HDL-C were higher in females than in males. Correlation matrix between 11 biomarkers was illustrated in Additional file 3: Table S3. The results of EFA were showed in Table 2 with explained variance and cumulative variance, this suggested that six synthetic latent predictors (SLPs) could explain $81.55 \%$ and $79.65 \%$ of total variance for males and females respectively. According to the criteria of analytical interpretation stated in the statistical analysis section, they were named as inflammatory factor (IF), erythrocyte parameter factor (EPF), blood pressure factor (BPF), lipid metabolism factor (LMF), obesity condition factor (OCF), and glucose metabolism factor (GMF) in both males and females. Of the six SLPs, IF was contributed by WBC \& LC \& NGC, EPF by Hb \& HCT, BPF by SBP \& DBP, LMF by TG \& HDL-C, OCF by BMI, and GMF by FBG.

Figure 1 showed the result of ROC analysis to predict 5 -year risk of MetS by the proposed predict model. It indicated that the AUC was up to $80.2 \%$ and $90.2 \%$ for males and females respectively in training set (seeing Figure $1 \mathrm{~A}$ and $1 \mathrm{~B}$ ). While $79.6 \%$ and $89.7 \%$ after 10 fold cross validation.

Figure 2 showed the 5-year $\mathrm{AR}$ matrix and RAR matrix for MetS by gender in the cohort $(n=1,565)$, specifically Figure $2 \mathrm{~A} 1$ and $2 \mathrm{~A} 2$ for males, and Figure 2B1 and $2 \mathrm{~B} 2$ for females. These matrices provide a convenient tool for conducting MetS prediction in health management and clinical practice. For example, a man aged 30-year-old and having AR of 0.233 has an EAR of 0.054 (0.233-0.179) and RAR of 1.301 (0.233/0.179), while a man aged 60-year-old and having an AR of 0.233 , has the EAR -0.187 (0.233-0.420) and RAR of 0.555 (0.233/ 0.420 ). These show that although their predictive probabilities for MetS over 5 years are the same, the younger man has a higher MetS risk compared to his peers, about 1.301 times than that of the average risk of 40-year-old population, indicating that changes in lifestyles and social intervention strategies are needed for him. Alternatively the MetS risk of the older man is lower than the average risk of the same age, only $55.5 \%$ of 
Table 1 Distribution of age and the eleven biomarkers between male and female with baseline metabolic syndrome

\begin{tabular}{|c|c|c|c|}
\hline & Male $(n=13345)$ & Female $(n=3212)$ & $P$ values \\
\hline & Mean \pm SD & Mean \pm SD & \\
\hline Age (years) & $49.00 \pm 13.09$ & $59.50 \pm 12.49$ & $<.0001$ \\
\hline body mass index $\left(\mathrm{kg} / \mathrm{m}^{2}\right)$ & $28.29 \pm 2.99$ & $28.27 \pm 3.10$ & 0.8241 \\
\hline systolic blood pressure $(\mathrm{mmHg})$ & $144.60 \pm 17.28$ & $150.40 \pm 20.54$ & $<.0001$ \\
\hline diastolic blood pressure $(\mathrm{mmHg})$ & $87.09 \pm 12.00$ & $81.76 \pm 11.99$ & $<.0001$ \\
\hline fasting blood-glucose (mmol/L) & $6.43 \pm 1.94$ & $6.65 \pm 2.09$ & $<.0001$ \\
\hline triglycerides (mmol/L) & $2.87 \pm 2.26$ & $2.42 \pm 1.53$ & $<.0001$ \\
\hline high-density lipoprotein cholesterol ( $\mathrm{mmol} / \mathrm{L})$ & $1.18 \pm 0.35$ & $1.32 \pm 0.35$ & $<.0001$ \\
\hline hemoglobin ( $g / L)$ & $157.70 \pm 10.82$ & $138.30 \pm 11.88$ & $<.0001$ \\
\hline hematocrit (\%) & $46.27 \pm 3.03$ & $41.65 \pm 3.18$ & $<.0001$ \\
\hline white blood cell count $\left(10^{9} / \mathrm{L}\right)$ & $7.18 \pm 1.67$ & $6.90 \pm 1.63$ & $<.0001$ \\
\hline lymphocyte $\left(10^{9} / \mathrm{L}\right)$ & $2.25 \pm 0.69$ & $2.24 \pm 0.68$ & 0.4432 \\
\hline neutrophile granulocyte $\left(10^{9} / \mathrm{L}\right)$ & $4.30 \pm 1.28$ & $4.13 \pm 1.27$ & $<.0001$ \\
\hline
\end{tabular}

the average risk of 60 -year-old population, indicating that he has a good health status compared with his peers.

Using the cut-off points showed in Figure 1A for males (0.2749) and Figure 1B for females (0.1181), people were classified as high-risk population ( $>$ the cut-off point value) or low-risk population ( $\leq$ the cut-off point value). The proportion of high-risk that comes with ageing in the general population $(n=92284)$ was drawn in Figure 3. Generally, the proportion of high risk subjects increase with age in both males and females. Nevertheless, the proportion of high-risk was higher in males than females before the age of 55, while it was the reverse after 55 .

\section{Discussions}

The routine health check-up based biomarkers for predicting MetS

Currently, several potential routine health check-up based biomarkers, such as $\mathrm{Hb}$ [17-19], HCT [17,18,28], WBC [20-27], LC [23,29] and NGC [23,29], were identified for predicting MetS/its components. Correlation matrix between 11 biomarkers was illustrated in Additional file 3: Table S3, which Shows the necessity of EFA. In this paper, we extracted 6 independent synthetic latent predictors (SLPs) by EFA from 11 routine health check-up biomarkers (BMI, SBP, DBP, FBG, TG, HDL-C, Hb, HCT, WBC, LC,

Table 2 Factor loadings by principal component analysis with varimax rotation on 11 routine health check-up biomarkers in MetS patients

\begin{tabular}{|c|c|c|c|c|c|c|c|c|c|c|c|c|}
\hline & \multicolumn{6}{|c|}{ Males $(n=13345)$} & \multicolumn{6}{|c|}{ Females $(n=3212)$} \\
\hline & IF & EPF & BPF & LMF & OCF & GMF & $\mathrm{IF}$ & EPF & BPF & LMF & OCF & GMF \\
\hline BMI & 0.050 & 0.017 & 0.108 & -0.042 & 0.954 & 0.007 & 0.016 & 0.001 & 0.184 & 0.080 & 0.873 & -0.013 \\
\hline SBP & 0.031 & -0.088 & 0.885 & -0.051 & -0.007 & 0.039 & 0.018 & -0.019 & 0.851 & 0.013 & 0.015 & 0.023 \\
\hline DBP & 0.001 & 0.206 & 0.813 & 0.122 & 0.134 & -0.101 & 0.005 & 0.155 & 0.786 & -0.012 & 0.120 & -0.065 \\
\hline FBG & -0.001 & -0.017 & -0.049 & 0.111 & 0.008 & 0.965 & 0.074 & 0.038 & -0.041 & 0.165 & 0.004 & 0.905 \\
\hline TG & 0.066 & 0.051 & -0.032 & 0.825 & 0.171 & 0.087 & 0.013 & 0.067 & -0.045 & 0.776 & 0.082 & 0.199 \\
\hline HDL-C & -0.050 & -0.043 & 0.093 & 0.794 & -0.239 & 0.027 & -0.076 & -0.039 & 0.131 & 0.583 & -0.546 & -0.027 \\
\hline $\mathrm{Hb}$ & 0.045 & 0.971 & 0.051 & 0.021 & 0.010 & 0.018 & 0.047 & 0.975 & 0.071 & 0.028 & 0.009 & 0.055 \\
\hline HCT & 0.119 & 0.957 & 0.041 & -0.012 & 0.017 & -0.040 & 0.095 & 0.969 & 0.074 & 0.045 & 0.013 & -0.017 \\
\hline WBC & 0.991 & 0.078 & 0.035 & -0.020 & 0.010 & 0.036 & 0.992 & 0.076 & 0.014 & 0.045 & 0.033 & 0.013 \\
\hline LC & 0.642 & 0.033 & -0.072 & 0.127 & 0.117 & -0.176 & 0.592 & 0.086 & -0.031 & 0.410 & 0.109 & -0.317 \\
\hline NGC & 0.853 & 0.073 & 0.086 & -0.094 & -0.058 & 0.144 & 0.881 & 0.040 & 0.033 & -0.173 & -0.025 & 0.197 \\
\hline$\%$ Variance explained & 22.15 & 15.87 & 13.34 & 12.93 & 8.88 & 8.37 & 22.21 & 16.21 & 13.15 & 11.12 & 9.01 & 7.95 \\
\hline Cumulative variance & 22.15 & 38.03 & 51.37 & 64.30 & 73.18 & 81.55 & 22.21 & 38.42 & 51.57 & 62.69 & 71.70 & 79.65 \\
\hline
\end{tabular}

BMI indicated body mass index; SBP, systolic blood pressure; DBP, diastolic blood pressure; FBG, fasting blood-glucose; TG, triglycerides; HDL-C, high-density lipoprotein cholesterol; Hb, hemoglobin; HCT, hematocrit; WBC, white blood cell count; LC, lymphocyte; NGC, neutrophile granulocyte; Factor1-Factor6 was called as inflammatory factor (IF), erythrocyte parameter factor (EPF), blood pressure factor (BPF), lipid metabolism factor (LMF), obesity condition factor (OCF), glucose metabolism factor (GMF). The bold character figures were factor loadings greater than 0.50 . 

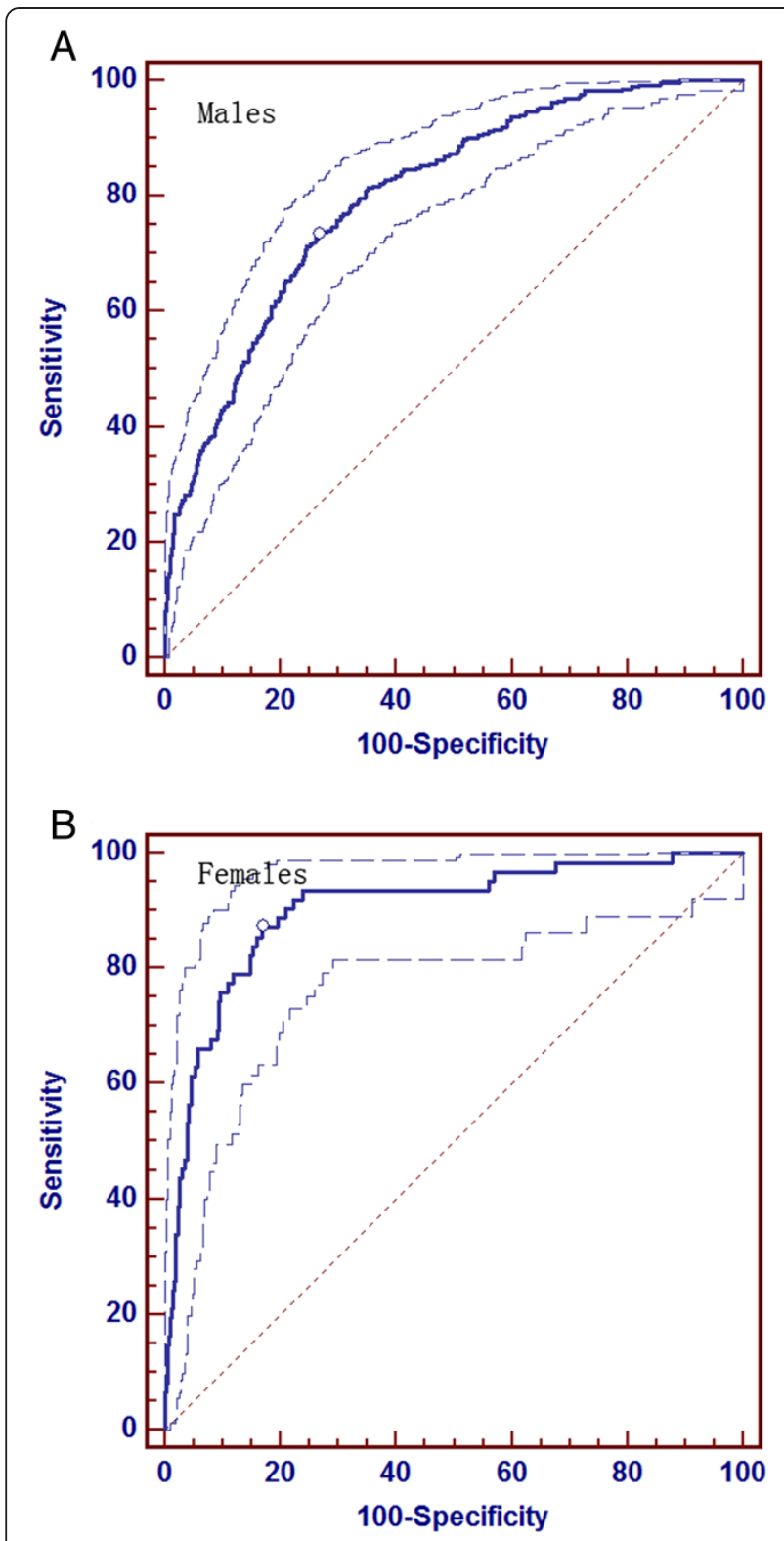

Figure 1 ROC curve for prediction of metabolic syndrome. A shows the predictive effect in males, B represents corresponding result in females. The dotted plots stand for $95 \%$ Confidence Interval. A: Area under the ROC curve (AUC) 0.802; Standard Error 0.0168 ; $95 \%$ Confidence Interval 0.776 to 0.826 ; $z$ statistic 17.916 ; Significance level P (Area $=0.5)$ 0.0001. Point with the highest accuracy showed sensitivity 73.4 and specificity 73.3 under the cut-off 0.2749. B: Area under the ROC curve (AUC) 0.902; Standard Error $0.0264 ; 95 \%$ Confidence Interval 0.874 to 0.925 ; $z$ statistic 15.233 ;

Significance level P (Area $=0.5)$ 0.0001. Point with the highest accuracy showed sensitivity 87.1 and specificity 83.0 under the cut-off 0.1181 .

NGC), not only with their specific clinical significances, but eliminating the multicollinearity between them. Each SLPs reflected the specific pathogenesis of MetS, with IF contributed by WBC \& LC \& NGC, EPF by Hb \& HCT,
BPF by SBP \& DBP, LMF by TG \& HDL-C, OCF by BMI, and GMF by GMF (see Table 2). The cumulative Variances explained by the six SLPs were up to $81.55 \%$ and $79.65 \%$ for males and females respectively. Particularly, the IF and EPF were identified as the key factors for the variation of MetS with their contribution proportion of $22.25 \% \& 15.87 \%$ in males and $22.21 \% \& 16.21 \%$ in females respectively. Pathogenically, both of them were strong associated with insulin resistance [33-36] which was the 'core' for MetS [37-39]. EPF was contributed by $\mathrm{Hb}$ \& $\mathrm{HCT}$. $\mathrm{Hb}$ is a carrier and buffer of nitric oxide (NO), and various compounds of $\mathrm{Hb}$ with $\mathrm{NO}$ can affect $\mathrm{Hb}$-oxygen affinity of the whole blood [40]. Disturbed NO synthesis may exert an adverse effect on endothelial dysfunction through the L-arginine-NO pathway [41]. Furthermore, endothelial dysfunction was reported to be associated with MetS $[42,43]$. HCT could change blood viscosity and peripheral resistance to blood flow, and further contribute to insulin resistance [44-46].

\section{Metabolic syndrome synthetic predictor and its application in MetS prediction}

At the end of the follow-up period, the cumulative incidence rate reach up to $22.2 \%$ ( $28 \%$ in males and $11.4 \%$ in females) (see Additional file 1: Table S1). Currently, three cross-sectional design based risk scores [12-14] and two cohort design based predictive models $[15,16]$ had been developed to predict MetS on different ethnicities. Although these predict tools obtain acceptable power with their AUC ranged from 0.724 to 0.827, their risk algorithm and visualization of risk assessment still had development potential for improving power, feasibility and practicability. In this paper we developed a routine health check-up cohort design based MetS synthetic predictor $(M S P)$ for predict 5 year risk of MetS in the frame work of Cox regression model. The MSP based predict model demonstrated good performance for predicting 5 years MetS with the AUC of 0.802 (95\% CI $0.776-0.826)$ in males and 0.902 (95\% CI 0.874-0.925) in females respectively, even after 10 fold cross validation, AUC was still enough high with 0.796 (95\% CI 0.7700.821 ) in males and 0.897 (95\% CI 0.868-0.921) in females. More importantly, the MSP was further used to construct the risk matrix with a series of risk warning indexes including average risk in population, AR \& RAR for subjects, and the cut-off curve for predicted MetS (see Figure 2). This matrix provided a feasible and practical tool for visualization of risk assessment in the prediction of MetS. As an example, for a woman at a given age who receives health check-up, the risk matrices can provide her with AR (Figure 2B1) and RAR (Figure 2B2) compared with the average hazard within the same age group in females, this may urge her to intervene risk factors for reducing risk of MetS. 


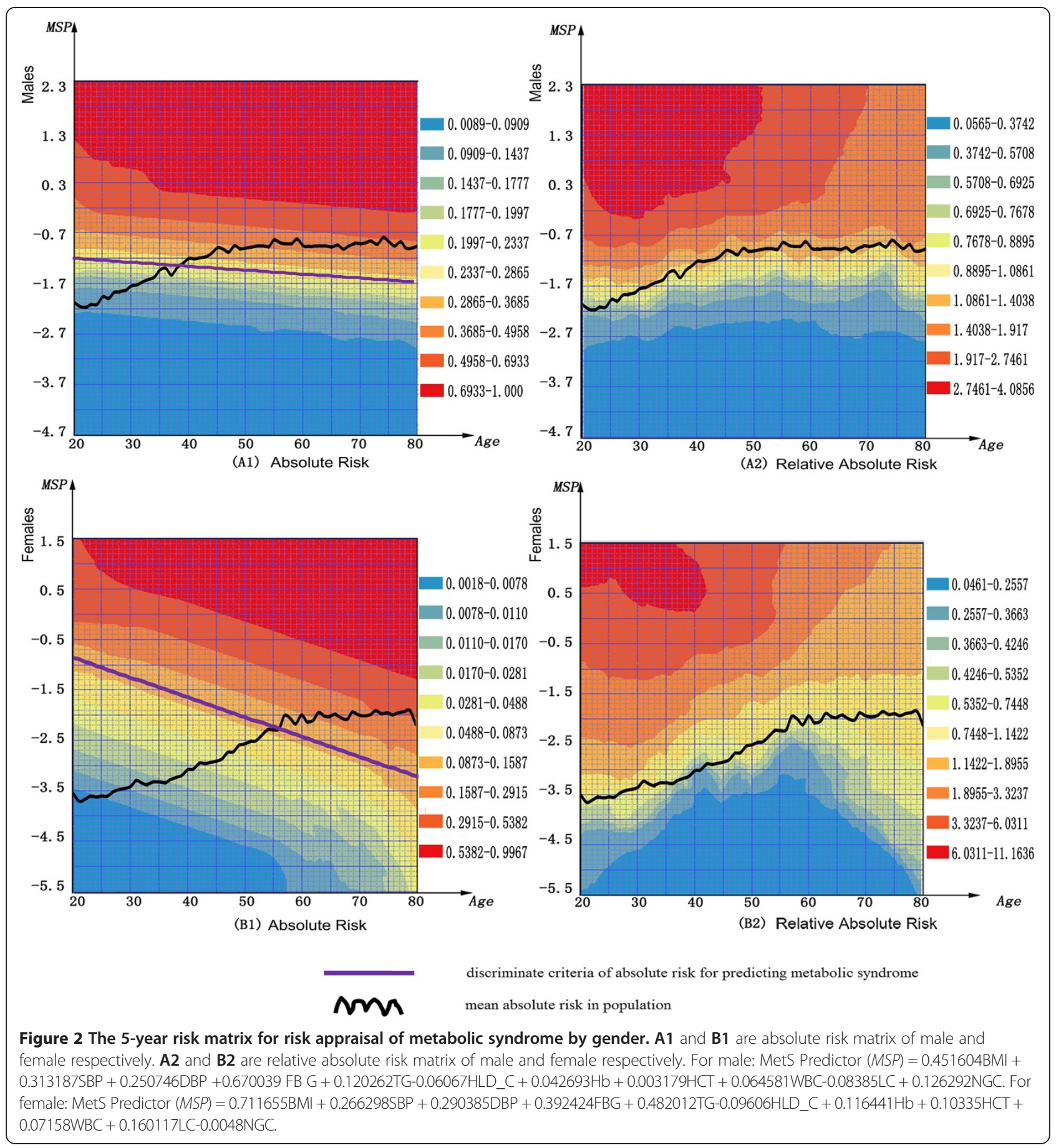

The risk distribution in urban Han Chinese population

The proportion of subjects with high-risk was higher in males than females before the age of 55, while it was in reverse after 55 (showed in Figure 3). Similar results have been obtained in the Korean population [47] with the demarcation point of 60 years old. In particular, the patterns of subjects with high-risk were quite different between males and females. The proportion of subjects with high- risk increased linearly with age in male population, while showed an $\mathrm{S}$ shaped curve in female population with the fastest growth period from 40 to 60 years old. This difference may be associated with women's menopause. Various studies indicated that natural menopause was associated with increased central adiposity [48], blood pressure [49-55], total cholesterol, LDL cholesterol and triglyceride levels $[50,56]$, which would further increase 


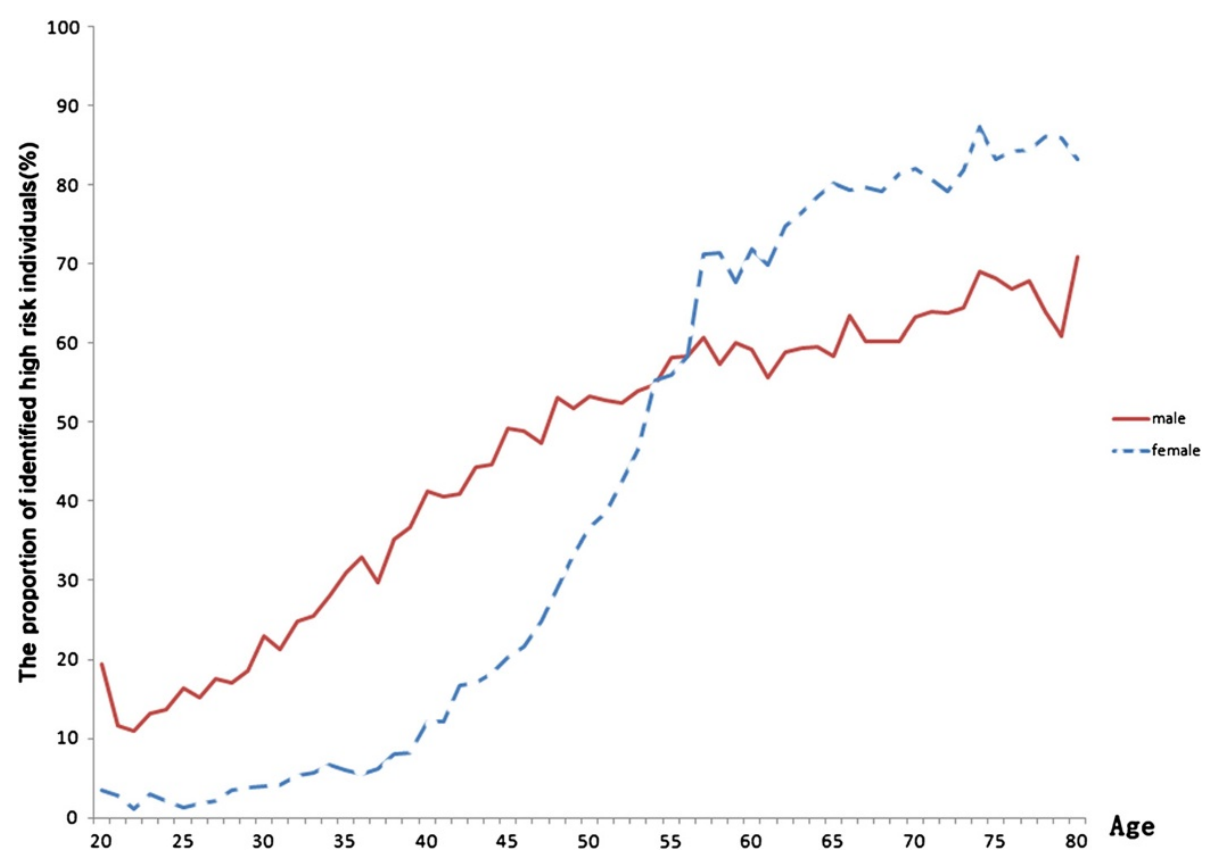

Figure 3 The metabolic syndrome risk appraisal result of 92284 subjects in routine health check-up system.

risk of MetS during the menopause transition years. The contribution of several metabolic components to the metabolic syndrome is different in males and females (see Additional file 2: Table S2).

We re-assessed the predictive ability using IF \& EPF alone and four classical MetS components respectively. Additional file 4: Table S4 showed these results, as expected, our proposed 6 SLPs still have the best performance. Actually, in China, health check up was embedded in "physical examination package" and usually the biomarkers can be obtained together. The Chinese government request every Health Examination Center that at least all biomarkers used in this manuscript must be tested during the health examination process.

\section{Limitations}

Study population was just employed urban residents, therefore the results may not extend to general population. In addition, five years follow-up was relatively short for predict long term risk of MetS.

\section{Conclusions}

In conclusion, MetS could be explained by six SLPs in Chinese urban Han population. The proposed MSP based predict model demonstrated good performance for predicting 5 years MetS, and the MetS-based matrix provided a feasible and practical tool for visualization of risk assessment in the prediction of MetS.

\section{Additional files}

Additional file 1: Table S1. The incidence rate of MetS in unaffected 1,565 subjects at baseline after a follow-up of five years.

Additional file 2: Table S2. The prevalence of the 4 basic components for both male and female metabolic syndrome groups.

Additional file 3: Table S3. Correlation matrix between eleven biomarkers.

Additional file 4: Table S4. The area under the ROC curves (AUC) by using different MetS predictors.

\section{Competing interests}

The authors declare that they have no competing interests.

\section{Authors' contributions}

In our work, FX and CZ designed the study and directed its implementation, including quality assurance and control. JL, FT and $\mathrm{HJ}$ did the clinical exam and collected the data. ZY and ZD helped to draft the manuscript. WZ and QC participated much of the above work and led the writing of the paper. All authors read and approved the final manuscript.

\section{Acknowledgements}

This work was co-supported by grants from the National Nature Science Fund (No.81273082) of China and Science \& Technology Development Projects of Shandong Province (2009GG20002035). The funding agencies were not involved in study design, analysis, and interpretation.

\section{Author details}

'Department of Epidemiology and Biostatistics, School of Public Health, Shandong University, Jinan 250012, China. ${ }^{2}$ Shengli Qilfield Central Hospital, Dongying 257034, China. ${ }^{3}$ Health Management Center, Shandong Provincial QianFoShan Hospital, Jinan 250014, China. ${ }^{4}$ The Second Hospital of Shandong University, Jinan 250033, China.

Received: 10 August 2014 Accepted: 15 January 2015

Published online: 31 January 2015 


\section{References}

1. Huang PL. A comprehensive definition for metabolic syndrome. Dis Model Mech. 2009;2(5-6):231-7.

2. Yusuf S, Reddy S, Ounpuu S, Anand S. Global burden of cardiovascular diseases: Part II: variations in cardiovascular disease by specific ethnic groups and geographic regions and prevention strategies. Circulation. 2001;104(23):2855-64.

3. Xi B, He D, Hu Y, Zhou D. Prevalence of metabolic syndrome and its influencing factors among the Chinese adults: the China Health and Nutrition Survey in 2009. Prev Med. 2013;57(6):867-71.

4. Sattar N, McConnachie A, Shaper AG, Blauw GJ, Buckley BM, de Craen AJ, et al. Can metabolic syndrome usefully predict cardiovascular disease and diabetes? Outcome data from two prospective studies. Lancet. 2008;371(9628):1927-35.

5. Arnlov J, Ingelsson E, Sundstrom J, Lind L. Impact of body mass index and the metabolic syndrome on the risk of cardiovascular disease and death in middle-aged men. Circulation. 2010;121(2):230-6.

6. Scott R, Donoghoe M, Watts GF, O'Brien R, Pardy C, Taskinen MR, et al. Impact of metabolic syndrome and its components on cardiovascular disease event rates in 4900 patients with type 2 diabetes assigned to placebo in the FIELD randomised trial. Cardiovasc Diabetol. 2011;10:102.

7. Gami AS, Witt BJ, Howard DE, Erwin PJ, Gami LA, Somers VK, et al. Metabolic syndrome and risk of incident cardiovascular events and death: a systematic review and meta-analysis of longitudinal studies. J Am Coll Cardiol. 2007:49(4):403-14.

8. He Y, Jiang B, Wang J, Feng K, Chang Q, Fan L, et al. Prevalence of the metabolic syndrome and its relation to cardiovascular disease in an elderly Chinese population. J Am Coll Cardiol. 2006;47(8):1588-94.

9. Mottillo S, Filion KB, Genest J, Joseph L, Pilote L, Poirier P, et al. The metabolic syndrome and cardiovascular risk a systematic review and meta-analysis. J Am Coll Cardiol. 2010;56(14):1113-32.

10. Singh AK, Kari JA. Metabolic syndrome and chronic kidney disease. Curr Opin Nephrol Hypertens. 2013;22(2):198-203.

11. Gluba A, Mikhailidis DP, Lip GY, Hannam S, Rysz J, Banach M. Metabolic syndrome and renal disease. Int J Cardiol. 2013;164(2):141-50.

12. Mohan V, Sandeep S, Deepa M, Gokulakrishnan K, Datta M, Deepa R. A diabetes risk score helps identify metabolic syndrome and cardiovascular risk in Indians - the Chennai Urban Rural Epidemiology Study (CURES-38). Diabetes Obes Metab. 2007;9(3):337-43.

13. Saaristo T, Peltonen M, Lindstrom J, Saarikoski L, Sundvall J, Eriksson JG, et al. Cross-sectional evaluation of the Finnish Diabetes Risk Score: a tool to identify undetected type 2 diabetes, abnormal glucose tolerance and metabolic syndrome. Diab Vasc Dis Res. 2005;2(2):67-72.

14. Heldgaard PE, Griffin SJ. Routinely collected general practice data aids identification of people with hyperglycaemia and metabolic syndrome. Diabet Med. 2006;23(9):996-1002.

15. Hsiao FC, Wu CZ, Hsieh CH, He CT, Hung YJ, Pei D. Chinese metabolic syndrome risk score. South Med J. 2009;102(2):159-64.

16. Yang $\mathrm{XH}$, Tao QS, Sun F, Cao CK, Zhan SY. Setting up a risk prediction model on metabolic syndrome among 35-74 year-olds based on the Taiwan MJ Health-checkup Database. Zhonghua Liu Xing Bing Xue Za Zhi. 2013;34(9):874-8.

17. Kawamoto R, Tabara Y, Kohara K, Miki T, Kusunoki T, Abe M, et al. Hematological parameters are associated with metabolic syndrome in Japanese community-dwelling persons. Endocrine. 2013;43(2):334-41.

18. Lohsoonthorn $V$, Jiamjarasrungsi W, Williams MA. Association of Hematological Parameters with Clustered Components of Metabolic Syndrome among Professional and Office Workers in Bangkok, Thailand. Diabetes Metab Syndr. 2007;1(3):143-9.

19. Wu S, Lin H, Zhang C, Zhang Q, Zhang D, Zhang Y, et al. Association between erythrocyte parameters and metabolic syndrome in urban Han Chinese: a longitudinal cohort study. BMC Public Health. 2013;13:989.

20. Chen W, Srinivasan SR, Xu J, Berenson GS. Black-white divergence in the relation of white blood cell count to metabolic syndrome in preadolescents, adolescents, and young adults: the Bogalusa Heart Study. Diabetes Care. 2010;33(11):2474-6.

21. Fan X, Liu EY, Freudenreich O, Park JH, Liu D, Wang J, et al. Higher white blood cell counts are associated with an increased risk for metabolic syndrome and more severe psychopathology in non-diabetic patients with schizophrenia. Schizophr Res. 2010;118(1-3):211-7.
22. Lee YJ, Shin YH, Kim JK, Shim JY, Kang DR, Lee HR. Metabolic syndrome and its association with white blood cell count in children and adolescents in Korea: the 2005 Korean National Health and Nutrition Examination Survey. Nutr Metab Cardiovasc Dis. 2010;20(3):165-72.

23. Meng W, Zhang C, Zhang Q, Song X, Lin H, Zhang D, et al. Association between leukocyte and metabolic syndrome in urban Han Chinese: a longitudinal cohort study. PLoS One. 2012;7(11):e49875.

24. Nakanishi N, Suzuki K, Tatara K. White blood cell count and clustered features of metabolic syndrome in Japanese male office workers. Occup Med (Lond). 2002;52(4):213-8.

25. Oda E, Kawai R. Comparison between high-sensitivity C-reactive protein (hs-CRP) and white blood cell count (WBC) as an inflammatory component of metabolic syndrome in Japanese. Intern Med. 2010:49(2):117-24.

26. Oda E, Kawai R. The prevalence of metabolic syndrome and diabetes increases through the quartiles of white blood cell count in Japanese men and women. Intern Med. 2009;48(13):1127-34.

27. Park JT, Chang TI, Kim DK, Choi HY, Lee JE, Kim HW, et al. Association of white blood cell count with metabolic syndrome in patients undergoing peritoneal dialysis. Metabolism. 2009;58(10):1379-85.

28. Sugimori $H$, Tomoda F, Koike $T$, Kinuno $H$, Kurosaki $H$, Masutani $T$, et al. Blood rheology and platelet function in untreated early-stage essential hypertensives complicated with metabolic syndrome. Int J Hypertens. 2012;2012:109830

29. Kim JA, Choi YS, Hong Jl, Kim SH, Jung HH, Kim SM. Association of metabolic syndrome with white blood cell subtype and red blood cells. Endocr J. 2006:53(1):133-9.

30. Lu YH, Lu JM, Wang SY, Li CL, Liu LS, Zheng RP, et al. Comparison of the diagnostic criteria of metabolic syndrome by International Diabetes Federation and that by Chinese Medical Association Diabetes Branch. Zhonghua Yi Xue Za Zhi. 2006;86(6):386-9.

31. Normann J, Mueller M, Biener M, Vafaie M, Katus HA, Giannitsis E. Effect of older age on diagnostic and prognostic performance of high-sensitivity troponin T in patients presenting to an emergency department. Am Heart J. 2012;164(5):698-705.

32. Perkins NJ, Schisterman EF. The inconsistency of "optimal" cutpoints obtained using two criteria based on the receiver operating characteristic curve. Am J Epidemiol. 2006;163(7):670-5.

33. Despres JP, Lemieux I. Abdominal obesity and metabolic syndrome. Nature. 2006;444(7121):881-7.

34. Sawada K, Krantz SB, Dessypris EN, Koury ST, Sawyer ST. Human colony-forming units-erythroid do not require accessory cells, but do require direct interaction with insulin-like growth factor I and/or insulin for erythroid development. J Clin Invest. 1989;83(5):1701-9.

35. Shoelson SE, Lee J, Goldfine AB. Inflammation and insulin resistance. J Clin Invest. 2006;116(7):1793-801.

36. Stonestreet BS, Goldstein M, Oh W, Widness JA. Effects of prolonged hyperinsulinemia on erythropoiesis in fetal sheep. Am J Physiol. 1989;257(5 Pt 2):R1199-204.

37. Reaven $\mathrm{GM}$, Chen YD. Role of insulin in regulation of lipoprotein metabolism in diabetes. Diabetes Metab Rev. 1988;4(7):639-52.

38. Ferrannini E, Haffner SM, Mitchell BD, Stern MP. Hyperinsulinaemia: the key feature of a cardiovascular and metabolic syndrome. Diabetologia. 1991;34(6):416-22.

39. Expert Panel on Detection, Evaluation, and Treatment of High Blood Cholesterol in Adults. Executive Summary of the Third Report of the National Cholesterol Education Program (NCEP) Expert Panel on Detection, Evaluation, and Treatment of High Blood Cholesterol in Adults (Adult Treatment Panel III). JAMA. 2001;285(19):2486-2497.

40. Zinchuk W, Pronko TP, Lis MA. Blood oxygen transport and endothelial dysfunction in patients with arterial hypertension. Clin Physiol Funct Imaging. 2004;24(4):205-11.

41. Kelm M, Rath J. Endothelial dysfunction in human coronary circulation: relevance of the L-arginine-NO pathway. Basic Res Cardiol. 2001;96 (2):107-27.

42. Singel DJ, Stamler JS. Chemical physiology of blood flow regulation by red blood cells: the role of nitric oxide and S-nitrosohemoglobin. Annu Rev Physiol. 2005;67:99-145.

43. Wei Y, Liu G, Yang J, Zheng R, Jiang L, Bao P. The association between metabolic syndrome and vascular endothelial dysfunction in adolescents. Exp Ther Med. 2013;5(6):1663-6. 
44. Facchini FS, Carantoni M, Jeppesen J, Reaven GM. Hematocrit and hemoglobin are independently related to insulin resistance and compensatory hyperinsulinemia in healthy, non-obese men and women. Metabolism. 1998;47(7):831-5.

45. Nakanishi N, Suzuki K, Tatara K. Haematocrit and risk of development of Type 2 diabetes mellitus in middle-aged Japanese men. Diabet Med. 2004;21(5):476-82.

46. Tamariz $L$, Young JH, Pankow JS, Yeh HC, Schmidt Ml, Astor B, et al. Blood viscosity and hematocrit as risk factors for type 2 diabetes mellitus: the atherosclerosis risk in communities (ARIC) study. Am J Epidemiol. 2008;168(10):1153-60.

47. Park E, Kim J. Gender- and Age-Specific Prevalence of Metabolic Syndrome Among Korean Adults: Analysis of the Fifth Korean National Health and Nutrition Examination Survey. J Cardiovasc Nurs. 2014. [Epub ahead of print]

48. Poehlman ET, Toth MJ, Gardner AW. Changes in energy balance and body composition at menopause: a controlled longitudinal study. Ann Intern Med. 1995;123(9):673-5.

49. Kannel WB, Cupples LA, Ramaswami R, Stokes JR, Kreger BE, Higgins M. Regional obesity and risk of cardiovascular disease; the Framingham Study. J Clin Epidemiol. 1991;44(2):183-90.

50. Rexrode KM, Carey VJ, Hennekens CH, Walters EE, Colditz GA, Stampfer MJ, et al. Abdominal adiposity and coronary heart disease in women. JAMA. 1998;280(21):1843-8.

51. Crawford SL, Casey VA, Avis NE, McKinlay SM. A longitudinal study of weight and the menopause transition: results from the Massachusetts Women's Health Study. Menopause. 2000;7(2):96-104.

52. Poehlman ET, Toth MJ, Ades PA, Rosen CJ. Menopause-associated changes in plasma lipids, insulin-like growth factor I and blood pressure: a longitudinal study. Eur J Clin Invest. 1997;27(4):322-6.

53. Gierach GL, Johnson BD, Bairey MC, Kelsey SF, Bittner V, Olson MB, et al. Hypertension, menopause, and coronary artery disease risk in the Women's Ischemia Syndrome Evaluation (WISE) Study. J Am Coll Cardiol. 2006:47(3 Suppl):S50-8.

54. Rosenthal T, Oparil S. Hypertension in women. J Hum Hypertens. 2000;14(10-11):691-704.

55. Staessen JA, Ginocchio G, Thijs L, Fagard R. Conventional and ambulatory blood pressure and menopause in a prospective population study. J Hum Hypertens. 1997;11(8):507-14.

56. Schubert CM, Rogers NL, Remsberg KE, Sun SS, Chumlea WC, Demerath EW, et al. Lipids, lipoproteins, lifestyle, adiposity and fat-free mass during middle age: the Fels Longitudinal Study. Int J Obes (Lond). 2006;30(2):251-60.

\section{Submit your next manuscript to BioMed Central and take full advantage of:}

- Convenient online submission

- Thorough peer review

- No space constraints or color figure charges

- Immediate publication on acceptance

- Inclusion in PubMed, CAS, Scopus and Google Scholar

- Research which is freely available for redistribution 